\title{
MEMÓRIAS DE UMA HISTÓRIA DE UM LEITOR
}

\author{
José Roberto Andrade Féres*
}

\begin{abstract}
RESUMO: Entre histórias e estórias, entre origens e a "quimera da origem" (Michel Foucault), entre memórias e esquecimentos, entre arquivar e deletar, entre formatar e transformar, entre livros e e-books, entre leitores e leitores de e-books, entre palimpsestos e touchscreens, entre ensaio e relato, entre $o$ que falta e o que excede, entre o que se veste com letras e o que se despe literalmente - este texto: trazendo à lembrança Peter Stallybrass (sobretudo "A vida social das coisas" e "O casaco de Marx") palavras que buscam tratar as pessoas como coisas e as coisas como pessoas, biografando alguns leitores a partir da biografia de um leitor de e-books e vice-versa.
\end{abstract}

PALAVRAS-CHAVE: Memória. Esquecimento. La Disparition. E-book. Peter Stallybrass.

Tornou-se um clichê dizer que nós não devemos tratar as pessoas como coisas. Mas trata-se de um clichê equivocado. O que fazemos com as coisas para devotarIhes um tal desprezo? E quem pode se permitir ter esse desprezo? (STALLYBRASS, 2008, p. 80).

Fazia pouco menos de um ano que ele havia sumido, meu caro leitor. Fazia pouco menos de um ano que meu caro leitor havia sumido. Era $L$ que me havia dado esse leitor. E é por isso mesmo que, para ser sincero, ele não havia sumido, eu é que havia dado sumiço nele. Eu o havia banido às profundezas do armário só posso supor que - para que eu não me lembrasse de L, justamente. Eis que resolvi desenterrá-lo dali.

Lembro de lhe ter contado a estranha sensação de asfixia, de estar soterrado em um dos episódios de desabamento do Germinal de Zola, embora estivéssemos confortavelmente recostados ao lado da piscina.

*Universidade Federal da Bahia, Salvador, Brasil. Imeio: andradeferes@yahoo.com.br 
Peter Stallybrass e O casaco de Marx. Diz-se ali que "as roupas [dos mortos] ainda ficam lá, penduradas em seus armários, sustentando seus gestos ao mesmo tempo confortadores e aterradores, tocando os vivos com os mortos" (STALLYBRASS, 2008, p. 10). Diz-se ali também que "é difícil para nós viver com os mortos, não sabendo o que fazer com as roupas nas quais eles ainda estão pendurados, habitando seus armários e suas cômodas; não sabendo como vestilos" (Idem, p. 34-35). Em que me concernem essas roupas, esses gestos, esses armários habitados por mortos? L não tinha morrido; $L$ não morreu. $L$ tinha sumido; $L$ sumiu. Era $L$ quem me havia dado o meu leitor, no qual dei sumiço logo que $L$ sumiu. $L$ não deixou suas roupas para trás, nos meus armários. $L$ mal viveu nesta casa, nesta casa não ecoam seus gestos. É em mim que seus gestos encontram ressonância, até hoje, passado mais de ano da data do seu sumiço. Mas, na época, sem haver vestígio ou rastro seu nesta casa, foi às profundezas do armário que bani o meu leitor, presente seu, de L. Eu o havia transformado na sua efígie. Eu precisava de um foco para o seu sumiço, um foco para a sua falta, e, na falta de roupas suas, o leitor que $L$ me havia dado tornara-se a sua efígie. Não sabendo como vestir $L$, a vestimenta que lhe dei foi a de um leitor, que guardei no armário, e aguardei - sem a mínima consciência de que era isso o que eu estava fazendo.

Lembro de estar na Chapada Diamantina, na rede, na pousada, me recuperando de um joelho maltratado pela "escalada" do dia anterior - "escalada" para quem vive no sedentarismo há anos, feito eu, lendo não sei o quê, enquanto você e os demais se aventuram em outra "escalada". Em um certo momento, minha leitura se torna dinâmica; na verdade, depois de várias páginas passadas em pouquíssimos segundos, sem que eu tenha feito o mínimo gesto, minha leitura é interrompida para que eu possa escrever, ali mesmo, no programa de anotações do leitor, este haicai:

\section{uma formiguinha}

vira as páginas do livro

que leio em meu Reader. 
Em geral, bem como a grande maioria dos smartphones, assim como o iPad, os tablets e tantos outros aparelhos eletrônicos que encontramos nos dias de hoje, sejam eles portáteis ou não, os leitores de livros digitais possuem uma touchscreen, uma tela tátil, uma tela que responde ao toque. Portanto, pode-se trocar a página do e-book com uma passada de dedo na tela; ou pode-se colocar em destaque uma palavra ou um trecho de texto pressionando-os por alguns segundos; e assim por diante.

\section{2}

Um pouco menos de um ano após o seu sumiço forçado, resolvi desenterrá-lo do armário, meu caro leitor: meu caro leitor poderia ajudar-me com algumas leituras eletrônicas que vinha fazendo no computador, que, convenhamos, não é o suporte mais cômodo no qual se ler, por exemplo, no banheiro. Desenterrei-o portanto, desenterrei meu caro leitor; e, como qualquer aparelho eletrônico que se abandona por um certo tempo, não consegui ressuscitá-lo sem, antes, dar-lhe uma boa descarga elétrica, ou melhor, recarga elétrica. Muito bem, logo, logo lá estava ele, redivivo, com o descanso de tela da minha última leitura, a capa de Méditations poétiques de Alphonse de Lamartine. E quando reabri tais Meditações poéticas, vi que eu havia quase terminado o livro, faltavam uns cinco ou seis poemas, e, na página em que havia parado, figurava "L'apparition".

\section{II}

Ainda sobre a tela de um leitor de livros digitais - também chamado de e-reader, ou leitor de e-books, além de ser tátil, ela geralmente - como nos leitores Kindle, Kobo ou Sony Reader, algumas das marcas mais vendidas - faz uso da tecnologia e-ink (tinta virtual). O que se pretende com a e-ink, visualmente, é fornecer uma experiência de leitura bastante semelhante àquela feita em livros ou periódicos de carne e osso, ou melhor, de papel e tinta. Já existe hoje a 
possibilidade de se encontrarem imagens coloridas a partir dessa tecnologia, mas o mais comum é o bom e velho preto e branco ou tons de cinza. Algumas das principais vantagens dessa tecnologia em relação às telas LCD (Liquid Crystal Display) - do iPad ou dos tablets, por exemplo - é que a e-ink depende de iluminação externa e, por conseguinte, o gasto de energia é mínimo, fazendo com que a bateria de um leitor dure vários dias até que se precise recarregá-la. A maior desvantagem de um e-reader - quando comparado a um iPad ou um tablet - é que ele não permite ao usuário muito mais do que ler, fazer anotações, escutar músicas e navegar na internet; geralmente ele não dispõe das mil e uma utilidades - e inutilidades - de um iPad ou um tablet.

**

Não, talvez não seja de fato o fato de eu tê-lo guardado no armário, meu caro leitor; talvez meu caro leitor é que houvera se transformado em armário - e cada uma das leituras, cada uma das lembranças, toda a memória do leitor, todos os arquivos salvos no leitor, eu havia depositado neles o peso das roupas que $L$ não havia deixado nesta casa. Houvesse deixado suas roupas, eu as teria jogado fora. Mesmo que o armário viesse a recriar "a presença fantasmática dos vestidos que não estão mais lá" (STALLYBRASS, 2008, p. 20), eu os teria jogado no lixo. A ausência das suas roupas, ausência presente nesse leitor que eu havia feito de armário - simbólico - e banido às profundezas de um armário - de verdade, essa ausência não se joga na lixeira tão facilmente - talvez, um pouco como as roupas de um morto, essa presença-ausência, à salvo, no armário.

3

Vasculhei por um instante os arquivos e verifiquei quanta memória restava no leitor, e não era muita. Eu o havia enchido não somente de livros - que geralmente ocupam um espaço mínimo, mas também de álbuns de música, sobretudo de música instrumental, pois às vezes me apraz uma trilha sonora para a leitura. No entanto, com tanto arquivo de áudio ocupando a memória do leitor, era necessário excluir alguns deles para que eu pudesse inserir os novos textos 
que queria ler. Sem contar que o leitor não estava respondendo bem aos meus comandos, talvez pelo excesso desses arquivos pesados de áudio. Então conectei-o ao computador. Excluí discos. Incluí novos livros. Então desconectei-o do computador. O leitor piscou, como de hábito, e pronto: nem os discos haviam sido excluídos nem incluídos os novos livros; de tudo aquilo que, na tela do computador, parecia ter sido efetivamente realizado, não havia surtido efeito algum no leitor; uma vez desconectado do computador, o leitor havia retornado à mesma configuração que havia mantido por quase um ano. Sua memória resistia - como que intocada.

Lembro que você sempre ficava um pouco mais na sala, assistindo a filmes, enquanto eu, a cada noite, ia para o quarto mais cedo e avançava rumo a mais uma - ao menos - das Mil e uma noites, das mil e uma narrativas inseridas umas nas outras para que a história nunca acabe, para que, a cada amanhecer, haja um cliffhanger e não se caia no abismo, jamais.

Repeti o procedimento várias vezes (excluir discos, incluir livros), seguindo o manual de instruções à risca - e nada. Como o leitor se mostrava arisco, arrisquei variações não mencionadas no manual do aparelho: conectar o cabo USB (Universal Serial Bus) ao computador e, em seguida, ao leitor ligado; conectá-lo e, só depois, ligar o leitor; desconectar o leitor do computador sem ejetá-lo antes... Tentei de tudo, e muito, e muito de tudo - e nada. O leitor parecia interagir perfeitamente com o computador, mas, uma vez desconectado, retornava à memória que havia guardado por quase um ano, por todo o tempo do seu exílio nas profundezas do armário. Sua memória resistia - tanto à exclusão quanto à inclusão do que quer que fosse.

Lembro de Ihe ter trocado por Esmeralda em vários momentos; não, pela mãe de Esmeralda - em sua solidão, em seu luto eterno, e equivocado, e pela NotreDame de Paris, com suas facetas de ensaio histórico, arquitetônico e ficção ao 
mesmo tempo, com a sua beleza corcunda, grotesca, de obra, por vezes, inclassificável.

Em um primeiro momento, cheguei a pensar em traçar aqui uma história do leitor. Mas descobri ao longo da pesquisa que há histórias demais sobre o leitor, algumas convergentes em vários aspectos e outras bastante divergentes. Mas acho que o mais interessante de tudo o que encontrei foi o seguinte: quase todos os textos que tentam capturar as origens de inúmeros dispositivos ou inventos na área da informática - inclusive do e-reader, no fim das contas, acabam mencionando um artigo chamado "As we may think" (1945), de Vannevar Bush, engenheiro estadunidense que foi um dos responsáveis pelo advento da bomba atômica. Deixo aqui a dica de leitura, contudo sem deixar de relembrar uma frase de Michel Foucault (2000, p. 18): "o que se encontra no começo histórico das coisas não é a identidade ainda preservada da origem - é a discórdia entre as coisas, é o disparate". Para que eu possa dar um exemplo dessa "quimera da origem" (Idem, p. 19), relacionando-a com o tema aqui proposto, toco no nome de Ana Elisa Ribeiro, que fez um estudo que nos alerta para o cuidado que deve ser tomado ao se atribuir "a ideia original sobre o hipertexto" e, consequentemente, uma certa paternidade da "World Wide Web" a Vannevar Bush: historiadores apontam que o "criador" da internet, em 1989, Tim Berners-Lee, "teria sido um não-leitor do artigo de Bush" (RIBEIRO, 2008, p. 48).

Lembro de leituras e mais leituras, estudos e mais estudos com os copistas Bouvard e Pécuchet, transformando toda a herança que Ihes fora legada por Flaubert, todo o seu capital financeiro, em capital cultural, até o esgotamento da totalidade da herança.

Por fim, acabei abandonando a ideia de me fazer passar por historiador e preferi muito mais me embrenhar nas florestas de símbolos da biografia, sobretudo tendo em mente as Vidas imaginárias de Marcel Schwob, que, além de transitar ali entre história e estória, entre realidade e ficção, acentua a importância de se prestar atenção naquilo e naqueles que não são considerados extraordinários. Compartilho do seu lamento de que, "infelizmente, os biógrafos em geral 
acreditaram que eram historiadores. E nos privaram assim de retratos admiráveis. Fizeram a suposição de que só a vida dos grandes homens podia nos interessar" (SCHWOB, 1997, p. 23). E é por isso que venho aqui traçar um pequeno retrato talvez não tão admirável assim, retrato sequer de um homem - grande ou pequeno, e, sim, de uma coisa, de um objeto, memórias de uma história de um leitor, um leitor que diz respeito a leituras de livros digitais (e-books), um e-reader, um e-reader em particular, o meu. Só não posso negar que, sendo esse leitor o meu leitor e, sendo eu o leitor desse meu leitor e, sendo você o leitor da leitura que faço sobre meu leitor e, talvez, sendo você $L$ (quem me deu esse leitor), todos esses leitores podem - e devem - imbricar-se uns nos outros.

Lembro de um introito absolutamente perfeito, da exposição magnífica de Balzac na sua Procura do absoluto, que eu não poderia morrer sem ter lido, ainda mais por tanto admirar Truffaut - admiração com a qual Ihe contagiei, cujo autobiográfico ou autoficcional Antoine Doinel constrói um altar para honrar Honoré, sua fonte de inspiração - e plagiário (por antecipação).

Depois de um bom tempo de tentativas malsucedidas de excluir e incluir arquivos no leitor, resolvi buscar no site do fabricante alguma possível atualização para o sistema do aparelho. Existem casos em que, após a constatação de alguma falha de sistema de várias unidades do mesmo modelo, o fabricante disponibiliza uma atualização que serve para corrigir o erro ou, ao menos, melhorar o funcionamento do produto. E, de fato, havia uma atualização a ser instalada. Fiz o download do arquivo e dei início à sua instalação no leitor. Na última etapa da instalação, apareceu o aviso de que o leitor seria reinicializado para que o processo se encerrasse. O leitor foi automaticamente reinicializado e pronto: "ocorreu um erro desconhecido. A instalação não pôde ser completada. Tente novamente". Tentei novamente e de novo, e de novo, - e nada: dado o aviso, lá estava meu leitor, novamente, com a configuração intacta, aquela de quase um ano atrás. Sua memória resistia - a mesma memória das profundezas do armário. 
Lembro de ter a leitura - de algum livro de poesia - interrompida por um rapaz que trabalhava na barraca de praia em que estávamos, o qual me advertiu que o salitre poderia danificar o meu leitor. Estaria aqui uma das razões do seu mau funcionamento?

III

Eu não seria capaz de explicar satisfatoriamente como funciona a tecnologia utilizada na tela de um leitor, a e-ink (tinta virtual). É para isso que existem sites como "how stuff works" (aqui no Brasil, "como tudo funciona": http://www.hsw.uol.com.br/). Mas, quando tenho um leitor nas mãos, o que me vem de imediato à mente é um brinquedo chamado "quadro mágico", um brinquedo que serve para desenhar e apagar - e redesenhar e apagar de novo uns desenhos com uns traços retilíneos impossíveis de resultarem em boa coisa. Lembra dele? Pelo que li por aí, é conhecido também como "lousa mágica" ou, em Portugal, "ecrã mágico". Foi inventado por um francês, André Cassagnes, e lançado primeiramente nos EUA, em 1960, com o nome "etch a sketch" (minha tradução seria algo como "risca um rabisco"). Do tamanho de um caderno de folhas A4, ele tem uma tela acinzentada e dois botões giratórios, um que comanda o traçado no sentido horizontal e o outro na vertical. Conseguiu lembrar? É o melhor que posso fazer por ora. Melhor que isso, só no Google. Enfim, visualmente, a e-ink sempre me faz lembrar dele, embora as duas tecnologias sejam bem diferentes, uma é mecânica e a outra eletrônica. Mas o que mais me faz lembrar dele é o seguinte: no quadro mágico, quando você termina um desenho e quer fazer outro, você chacoalha o brinquedo até a tela voltar a ficar em branco; no leitor de e-book, a cada mudança de página, a tela dá uma piscadela, tudo fica preto por um piscar de olhos, como se a tela precisasse ser varrida por uma pálpebra para, só então, acolher o que vem a seguir.

Lembro de Sal Paradise na estrada, indo - não a Denver, não de caminhão, não rumo a Dean Moriarty ou Marylou, não, sim, a Confins, em um ônibus executivo, rumo a um avião para lhe ver, sim, para ver você. 
Quando penso a gênese com Louis Hay, recordo palavras que cita de Julien Gracq: "um livro nasce de uma insatisfação, de um vazio" (HAY, 2007, p. 63). Apuds à parte, recordamos outras, agora de Raúl Antelo (2011, p. 157): "toda frase lida é, literalmente, uma transposição, uma tradução, o vestígio de um corpo ausente que esteve all". Que esse "corpo ausente" aqui presente seja o do autor (eu mesmo ou outro), o de autores, o de um leitor (o meu ou outro), o de leitores, o de L, ou o de L's, este texto (que não tem pretensão de se tornar um livro) também "nasce de uma insatisfação, de um vazio" e de uma tentativa de transpor, de traduzir, de ser "o vestígio de um corpo ausente" que está aqui presente. Caso contrário, por que teria eu, há uma semana, escrito um artigo sobre a onipresença da ausência de Aquiles na llíada? Por que estaria eu traduzindo um livro em que a vogal proibida (ausente) é (re)velada por todos os lados, fazendo dela, igualmente, uma presença-ausência constante? Por que estaria eu discorrendo aqui sobre um e-reader, um leitor eletrônico, mas também se traduzido ao pé da letra, um leitor de vogais $e$, sendo que a letra $e$ não pode aparecer no romance que estou traduzindo? E por que esse e-reader do qual falo teimou tanto em guardar memórias que, sempre que incomodadas por algum intento meu de apagá-las, tacam na minha cara, sem nenhum pudor, um poema de Lamartine que se chama "L'apparition" (a aparição), enquanto o romance que venho traduzindo intitula-se La Disparition (o desaparecimento, O Sumiço)?

\footnotetext{
Peut-être [...]

Que le jour est un œil qui répand la lumière,

La nuit, une beauté qui voile sa paupière;

Et qu'enfin dans le ciel, sur la terre, en tout lieu,

Tout est intelligent, tout vit, tout est un dieu.

(Alguns versos de "La mort de Socrate",

Partie 3 de Méditations poétiques de Alphonse de Lamartine)

Pode ser $[\ldots]$

Que o dia seja um olho a espalhar claridade,

A noite, sua pálpebra, um véu de beldade;

E enfim que, em todo canto, na terra, nos céus,

Haja alma e vida em tudo, tudo seja um deus.

(Tradução minha: alguns versos de "A morte de Sócrates",
} 
Após o fracasso das tentativas de atualização do sistema do leitor, resolvi formatar sua memória, ou seja, apagar todas as informações ali contidas, todos os livros que já havia lido nele - e os que ainda não, todas as anotações que havia feito nele, todos os álbuns que ali estavam, tudo. Claro que tomei a precaução de, primeiro, conectá-lo novamente ao computador e fazer um backup, uma cópia de segurança daquilo que ele continha. Feito isso, desconectei-o mais uma vez e, depois de pesquisar no manual como proceder à formatação da memória do leitor, fi-lo - nem tanto porque qui-lo, formatei-o. Terminada a formatação, não lembro bem se ele foi reinicializado automaticamente ou se simplesmente deu a sua piscadela habitual. Só sei que nada havia acontecido: meu leitor recusava qualquer interferência na sua memória, teimando em mantêla intacta, exatamente a mesma memória de quase um ano atrás, aquela de quando eu o havia banido às profundezas do armário, pouco depois do sumiço de L. Lá estava ele, com o descanso de tela da sua última leitura, a capa de Méditations poétiques de Alphonse de Lamartine, ainda na mesma página, na qual figurava o poema "L'apparition".

Eu - tentando ser o arconte desse meu caro leitor, do arquivo que é esse ereader meu, meu - particular, pessoal, íntimo - "arkheîon grego: inicialmente uma casa, um domicílio, um endereço, a residência dos magistrados superiores, os arcontes, aqueles que comandavam", onde "se depositavam então os documentos oficiais" (DERRIDA, 2001, p. 12), e, aqui, os meus oficiosos documentos... Eu - tentando exercer meu poder, meu poder de escolha sobre o que constituirá o meu arquivo, sobre quais memórias ficam e quais devem partir... $\mathrm{E}$ o meu leitor - recusando-se, terminantemente, a submeter-se a meu poder... $\mathrm{E}$ o poder é de quem, afinal, é de quê?... Mas tentei, tentei formatar, tentei apagar, tentei esquecer... E é preciso um esforço tremendo para se esquecer que a 
memória é também um "mecanismo de eliminação: a memória é um mecanismo de esquecimento programado" (MENESES, 2007, p. 23)... Programei o esquecimento, sim, esqueci - consciente ou inconscientemente, pouco importa o meu leitor por quase um ano. Mas falhei na programação: não é fácil formatar uma memória; não é fácil formatar um esquecimento...

Lembro de estar sozinho, no sofá da sua sala, desfrutando dos inesgotáveis -e sádicos - infortúnios advindos da virtude de Justine, até o ponto de ser necessário um deus ex machina dos infernos para que a pobre Justine descansasse em paz.

IV

A tela de um leitor me lembra também um outro brinquedo, muito parecido com o "quadro mágico", mas mais velho que ele, que serviu até mesmo de matériaprima para um texto de Freud: "Uma nota sobre o bloco mágico". O "bloco mágico" é uma prancheta sobre a qual se escreve ou desenha com a ajuda de um objeto que não deve ter tinta e nem ser muito pontiagudo para não marcar ou rasgar a película transparente que fica presa em uma das suas bordas. Terminado o desenho ou o que quer que seja, é só levantar essa película, baixála novamente e, voilà, um novo desenho pode ser feito. Mas o que mais me atrai nisso tudo é que, tanto no quadro mágico quanto no bloco mágico, bem como no leitor, com sua moderna e-ink, em alguns momentos, a "nova" tela deixa transparecer alguns traços da "antiga": a "nova" imagem ou o "novo" texto - ou a "nova" memória, nunca são novos, nunca poderão apagar por completo aquilo que os antecedeu, trazem sempre traços, rastros do passado - tal qual minha brincadeira com quadros e blocos mágicos e leitores, nada mais que "novos" palimpsestos.

7

Depois de tanta tentativa de interferir na memória do leitor (inclusão e exclusão de arquivos, atualização do sistema, formatação), depois de tudo - e nada, tomei a 
decisão que devia ter tomado desde o início: meu leitor tem uma entrada para cartões de memória, um slot micro-SD (Secure Digital), então deixei sua memória interna em paz e inseri nele um novo cartão de memória. Deixei de tentar apagar, optei por expandir. Suas antigas memórias - retrógradas ou não - ainda estão lá, podem ser consultadas, aproveitadas e reaproveitadas, até mesmo - pela primeira vez - descobertas, já que há tanto ali em que eu jamais toquei. Mas novas memórias - recentes ou não - convivem hoje com as antigas, lado a lado.

Lembro do Apanhador no campo de centeio, o livro preferido de uma amiga predileta, quase irmã, da qual fui me afastando pouco a pouco, logo que conheci você, e com a qual retomei a amizade (oficialmente: facebookianamente - basta cavar o arquivo que é minha linha do tempo...) no exato dia em que dei sumiço no leitor, esse presente que ganhei de você. Sei da data exata, pois é para a configuração daquele dia (22/10/2012) que o leitor teima em voltar até hoje, sempre que tento fazer alguma intervenção na sua memória interna.

Se escrevi este texto que meu caro leitor tem sob os olhos é porque algo me falta e tudo o que posso oferecer é um esboço de tradução dessa falta, dessa insatisfação, desse vazio que me preenche e preenche estas folhas, preto no branco, mas sem muita clareza, só o suficiente para que novas e velhas memórias se traduzam e retraduzam em retrógradas ou recentes presençasausências. Peter Stallybrass (2008, p. 48), com razão, afirma que, tendo Marx que penhorar seu casaco em várias ocasiões e, assim, não podendo ir ao Museu Britânico realizar a pesquisa para a escrita de O Capital, "seu casaco determinava diretamente que trabalho ele podia fazer ou não. [...] As roupas que Marx vestia determinavam assim o que ele escrevia". Porém, principalmente quando me retorna à memória "a presença fantasmática" (Idem, p. 20) das roupas de um morto no armário esvaziado, arrisco um adendo às palavras de Stallybrass: o casaco de Marx, sua roupa, determinava, sim, o que ele escrevia; no entanto, ainda mais determinante para a sua escrita deve ter sido a necessidade de, tal qual qualquer outro operário, penhorar e reaver sem cessar o seu casaco para 
poder viver; portanto, ainda mais determinante deve ter sido a necessidade de conviver com a ausência desse casaco, com sua presença fantasmática, com sua falta, com seu vazio para poder viver, para sobreviver - para escrever: o que Marx não vestia também determinava o que escrevia.

\section{MEMORIES OF A STORY OF A READER}

ABSTRACT: Neither history nor story, neither origins nor the "origin's chimera" (Michel Foucault), neither memories nor oblivion, neither archives nor deletion, neither formatting nor transforming, neither books nor e-books, neither readers nor e-readers, neither palimpsests nor touchscreens, neither essay nor narrative, neither that which is missing nor that which exceeds, neither what is dressed with words nor what is literally undressed, but something in between - this text: remembering Peter Stallybrass (specially "Worn world" and "Marx's coat"), words that try to treat people as things and things as people, writing the biography of some readers through the writing of an e-reader biography, and vice versa.

KEYWORDS: Memory. Oblivion. La Disparition. E-book. Peter Stallybrass.

\section{REFERÊNCIAS}

ANTELO, Raúl. O tempo do arquivo não é o tempo da história. In: SOUZA, Eneida Maria de; MIRANDA, Wander Melo (Org.). Crítica e coleção. Belo Horizonte: Ed. UFMG, 2011. p.155-175.

DERRIDA, Jacques. Mal de arquivo. Tradução de Cláudia de Moraes Rego. Rio de Janeiro: Relume Dumará, 2001.

FOUCAULT, Michel. Nietzsche, a genealogia e a história. In: Microfísica do poder. Organização e tradução de Roberto Machado. 15 ed. Rio de Janeiro: Graal, 2000. p.15-37.

HAY, Louis. Pensar a gênese. In: A literatura dos escritores: questões de crítica genética. Tradução de Cleonice Paes Barreto Mourão. Belo Horizonte: Ed. UFMG, 2007. p. 35-89.

MENESES, Ulpiano Bezerra de. Os paradoxos da memória. In: MIRANDA, Danilo santos de (Org.). Memória e cultura: a importância da memória na formação cultural humana. São Paulo: Edições SESC-SP, 2007. p. 13-33.

RIBEIRO, Ana Elisa. Hipertexto e Vannevar Bush: um exame de paternidade. Informação e Sociedade: estudos. João Pessoa, v. 18, n. 3, p. 45-58, set./dez. 2008. Disponível em: <http://www.ies.ufpb.br/ojs/index.php/ies/article/view/1811>. Acessado em: 31 mai. 2014. 
SCHWOB, Marcel. Vidas imaginárias. Tradução de Duda Machado. São Paulo: Ed. 34, 1997.

STALLYBRASS, Peter. 0 casaco de Marx: roupas, memória, dor. 3 ed. Organização e tradução de Tomaz Tadeu. Belo Horizonte: Autêntica, 2008.

Texto recebido em: 31/05/2014.

Texto aceito em: 14/07/2014. 